\title{
Species Transformation Through Reconstruction: Reconstruction Through Active Reaction of Organisms
}

\author{
Translated by Alexander Böhm and Jan Baedke
}

\author{
Hans Böker ${ }^{1}$ \\ Published online: 8 April 2021 \\ (c) The Author(s) 2021
}

\begin{abstract}
Comparative biological morphology, incorporating the study of active reaction, is contrasted with genetics as the study of passive mutation. Geneticists investigate anatomical characters, never anatomical constructions, which are capable of reorganization when the biological-morphological equilibrium of the organism has been disturbed. The anatomy of Opisthocomus cristatus and Stringops habroptilus demonstrate that three successive disturbances in the bio-morphological equilibrium are reacted to purposively by anatomical reconstruction. These reactions are no accidental mutations, but are anatomical reactions, related to, and affecting, the organism as a whole. In sharp contrast to such anatomical reaction, resulting, during phylogeny, in reorganization, are the "technics" [i.e., mechanistic bases] of individual development. The hereditary process is, like every physiological or embryological process, a fixed mechanism, which remains constant until an active reaction leads to reconstruction and at the same time an appropriate change of the mechanisms. The remolding of species is therefore no passive, "technical" process, but a creative act of the organisms themselves. [Original English abstract; not translated.]
\end{abstract}

Keywords Active reaction $\cdot$ Hans Böker $\cdot$ Organism $\cdot$ Translation $\cdot$ Umkonstruktion

According to the dominant view, mutation is the most important factor of [evolutionary] species transformation. ${ }^{1}$ As the second factor orthogenesis is usually cited, which is understood to be the linear progression of change on a predetermined path. The formation of new species through species hybridization, ${ }^{2}$ however, now finds barely any defenders, because the crossing of wild type species that yield fertile

Translators: Alexander Böhm ${ }^{1}$ (alexander.boehm@rub.de) and Jan Baedke ${ }^{1}$ (jan.baedke@ rub.de), ${ }^{1}$ Department of Philosophy I, Ruhr University Bochum, Bochum, Germany. This article is the first translation into English of "Artumwandlung durch Umkonstruktion, Umkonstruktion durch aktives Reagieren der Organismen" (1935, Acta Biotheoretica 1:17-34) by Hans Böker. The original article is available as electronic supplementary material to the companion essay by Fábregas-Tejeda, Nieves Delgado, and Baedke (https://doi.org/10.1007/s13752-020-003707).

Hans Böker

https://www.kli.ac.at/en

1 Anatomical Institute of the University of Jena, Jena, Germany offspring has thus far never been proven beyond doubt. Documented fertile crosses are not cases of [new] species, but only of races of a species or, to be more precise, of components of a "circle of form" ${ }^{3}$ (Hartert and Stresemann 1927).

Mutation and orthogenesis have in common that they interfere with the fate of organisms and that they expose changing animals to selection, to the struggle for survival, retaining the fittest, best adapted forms, and destroying the

\footnotetext{
$\overline{1}$ Böker used the term "Artumwandlung," which was later described as "Anagenese" (anagenesis), i.e., the transformation of an ancestral species without splitting into several, new species (see Rensch B (1947) Neuere Probleme der Abstammungslehre. Enke, Stuttgart; Huxley J (1953) Evolution in action. Harper \& Brothers, New York).

2 Original: "Artbastardierung."

3 According to Otto Kleinschmidt's typological theory of "Formenkreis" (circle of form), species diversity should be interpreted as a hierarchically organized system of geographically distinct entities (forms). A "Formenkreis" more or less represents a species, but each "circle" is understood to be closed and constant, with a clearly limited range of variation.
} 
others. Mutation is here either subject to chance, i.e., undirected, or it is guided to a limited extent, when just a limited range of options is available (Kühn 1935, p. 71). In contrast, orthogenesis implies that organisms subjected to it can only change in a previously determined direction. Random mutation, mutation with limited variance, and orthogenesis blend into one another seamlessly. By reviewing publications on documented mutations, for which one can draw on the compilation by O. Naegeli in 1934, one will find the following:

The vast majority of known mutations concern hereditary defects, i.e., they create pathological conditions that obviously cannot be of any future relevance, as their bearers usually turn out to be nonviable, or not competitive and thus are eliminated. They usually affect domesticated animals and plants, not wild types. Those mutations, however, that have a positive value, or that at least appear neutral, mainly concern exterior bodily features, i.e., they consist in special characteristics of color and shape developed by the ectoderm, and so their biological relevance lies at most in species and sex recognition.

Characteristic examples of this are found in the overview of 24 studies of mutations in birds by E. Sresemann [sic] ${ }^{4}$ (1926). Another example is the large variability of coloration and markings in the small fish Lebistes, which is inherited following Mendel's laws (Kyle 1926). These mutations concern anatomical features that are entirely irrelevant to the lives of the animals.

Nevertheless, most leading geneticists assume a purely "singular-mutational" formation of species, i.e., they believe that the mutation theory in combination with the theory of natural selection can explain even complex processes of adaption. This view naturally encounters difficulties, and thus some geneticists have reached a point where they have to seriously consider, "whether the only consistent solution of the discrepancy is to give up the deductive theory of evolution" (Heribert-Nilsson, cited in Plate 1933).

On the other side we find researchers who want to explain the occurrence of complex adaption through the "inheritance of acquired characteristics," i.e., through "Lamarckism," which does not leave the transformation of species to chance, but understands it as directly influenced by use and disuse.

One position seems to exclude the other. Because of this, Goldschmidt (1928) states that within the Mendelian theory of evolution there is no room for the inheritance of acquired characteristics since the latter would be a logical impossibility within the framework of the genotype theory! But many researchers emphasize, following Naegeli (1934), that even though

inheritance of acquired characteristics appears unproven to many influential researchers, and the

\footnotetext{
$\overline{4}$ The correct name is "Stresemann."
}

available material of observation is insufficient for a conclusion of such fundamental importance, it nonetheless has not been entirely disproven either. We are only forced to exercise utmost caution and criticism, given the existing errors and fallacies in this field.

The main objection against the inheritance of acquired characteristics is that these phenomena are not about changes in the genotype, but always only about the activation of potential dispositions of the existing tolerance range. The literature that takes a stand for or against the inheritance of acquired characteristics, or tries to mediate between the two, has grown so voluminous that one might get the impression that following current trends no agreement will be reached. A fundamental mistake must somehow underlie the entire issue, i.e., something about the initial question must have been wrong. Bertalanffy (1932) already expressed this quite clearly by ascertaining that this issue entails a logical problem and that in genetics and Lamarckism two different ways of "reasoning about the world" collide with one another, one static and one dynamic, and that consequently, an experimental decision is fundamentally impossible.

In what follows, I seek to bridge the dichotomy by countering "exact" genetics as a theory of passive mutation with comparative biological morphology $y^{5}$ and its theory of active reaction. ${ }^{6}$

For years, I have emphasized in my work (for literature see Böker 1935) the inherent dichotomy between the anatomical trait on one hand and the anatomical construction on the other, and that there are two very different types of species change, namely one based on the change of singular traits, which are generally irrelevant for the life and adaptation of the animal, and another species transformation that occurs through the reconstruction ${ }^{7}$ of an anatomical structure, which immediately renders the animal newly adapted.

A beautiful example of the first type of potential species change is carrion and hooded crows, which, on the outside, are strongly differentiated, but in terms of their anatomy or, more correctly, their anatomical structures, remained entirely of the same species. ${ }^{8}$ If one were to pluck these

\footnotetext{
5 Original: "vergleichende biologische Morphologie."

6 Original: "Lehre von der aktiven Reaktion."

7 Böker translates the term "Umkonstruktion" as "re-construction" in the English abstract of this paper. The German prefix "Um-" in contrast to the English "re-" better grasps the idea that the morphological constitution of the organism is changed in novel ways, not that old morphologies are maintained or reestablished. What is actually maintained or restored through an "Umkonstruktion" is an equilibrium state or harmony within the whole organism and between the organism and its environment, despite environmental perturbations (see below).

${ }^{8}$ Böker presupposes here that the carrion crow (Corvus corone) and the hooded crow (Corvus cornix) are similar geographical races of one species. Today, researchers have elevated these two taxa to full species.
} 
birds, nobody would be able to tell apart the outwardly so easily distinguishable birds.

In opposition to this stands the example of species transformation through reconstruction that is displayed by the ontogenesis of the anterior extremities of the mole, or the specific anatomical features in the sungrebe Heliornis fulica (Böker 1935, p. 211; 1932, p. 261). Plate (1932) therefore states:

In its present state, the mutation theory cannot address the most important problems of evolution, because genetics cannot reach the hereditary units ${ }^{9}$ of the organs, and because phyletic processes cannot be treated experimentally. The theory of descent must therefore still borrow its facts and conclusions first and foremost from comparative morphology, chorology and ecology.

How different this sounds compared to the sentence of Goldschmidt (1928):

The change can only take place in such a way that suddenly and without transition new units of inheritance occur in the hereditary material, and old ones disappear or existing ones change. And it is this very assumption, which has dominated the biological sciences in modern times under the name of mutation theory. It becomes clear that these issues have far-reaching consequence, whose exact investigation should lay the most important foundation of the theory of descent.

Geneticists conducting experimental research in laboratories and experimental gardens just never examine anatomical constructions! This explains why geneticists on one side and morphologists on the other so frequently cannot understand each other and are very hostile to one another.

They both work with entirely different materials, the "exact" geneticist with neutral anatomical traits; the morphologist, who seeks to understand phylogenetic phenomena, with anatomical constructions. To exemplify this, let us consider an example that I published six years ago already (Böker 1929, p. 178), which, however, has attracted nearly no attention so far.

The hoatzin Opisthocomus cristatus and the kakapo Stringops habroptilus ${ }^{10}$ are impaired in their ability to fly to different degrees; both have an enormously big crop that is not

\footnotetext{
9 Original: "Erbträger."

10 Stringops habroptilus is today known under the species name Strigops habroptilus and Opisthocomus cristatus is known as Opisthocomus hoazin. The taxonomic position of Opisthocomus hoazin has been debated since the late 18th century (including its relation to Stringops habroptilus), and today it is still far from clear.
}

located on the neck above the chest opening as in other birds, but is located in the area of the chest, which heavily affects the keel of the sternum and chest muscles. If we want to explain these facts, we must first, through genetic-constructive reasoning, capture the now existing anatomical construction. Then, by drawing on sets of biological-anatomical comparisons and investigations of ontogenetic sequences, we must trace back the reconstructions that occurred through phylogenesis (Böker 1935, p. 12).

Therefore, we must start from the "type" as the primary state or we must trace back to this type. ${ }^{11}$ Because the hoatzin is anatomically a cuckoo, and not a chicken as the German name suggests, ${ }^{12}$ and since, some time ago, the kakapo obviously must have lived and been constructed like common cockatoos, the original way to fly for both species was a primary and relatively well-developed lifting flight. So, the original type could be clearly characterized by this (Böker 1935, p. 112). The original food source of all birds consisted of insects and other lower animals, as well as fruits.

The first cause for a radical disturbance of the biological-morphological equilibrium (Böker 1935, p. 8) in the ancestors of today's Opisthocomus was a change of diet, especially a transition towards eating very hard leaves. In the ancestors of the kakapo, the disturbance entailed not only a change of diet but also the consequently emerging necessity of food storage, as the kakapo now subsists on hard, wooden plant foods, while its original diet must have consisted of fruits and buds, as in cockatoos. What caused this change of diet in both species is unknown as of yet until paleobotanical and paleoclimatological research in tropical South America and New Zealand helpfully steps in. Whether this change occurred voluntarily or was enforced on the birds is ultimately not important for the anatomical consequences.

The first anatomical reaction to the change of diet consisted in the formation of a large S-shaped crop in both birds. As in galliforms and many other birds, the crop in Stringops serves as a repository to soften the plant food crushed by the beak, which is then digested chemically in the stomach and intestinal tract. Opisthocomus takes smaller and bigger bites out of hard leaves that are swallowed as a whole, but then they are mechanically ground down by the muscular crop into a fine enough consistency to be digested easily and rapidly in the gastrointestinal tract. In the kakapo, the crop is very large and heavy, because it must store food for a long period of time; in the hoatzin this is because the crop 
is also very muscular. Because of this, a large contrast arises between the crop and the gizzard in the hoatzin, which can be seen in the following numbers: crop 13\%, gizzard $0.4 \%$ of the total weight (for details, see the cited original work, [Böker] 1929). The new diet led to another anatomical reaction with regard to the length of the intestinal tract; some numbers may illustrate this: if we convert the length of the torso to 20 in all compared birds, the intestinal tract length is 98 in a woodpecker, 146 in a hawk, 178 in a New World quail, 238 in a parrot, 327 in a pigeon, but 186 in a hoatzin and in contrast to that 587 in Stringops.

First, these reconstructions had the following physiological significance: In Opisthocomus the combined weight of head-neck and crop became larger than that of the second half of the body. The center of gravity, usually located in the area of the liver and heart, shifted toward the cranium. In Stringops the total weight was significantly increased by the heavy crop and intestines, but the crop alone became so heavy that it also shifted the center of gravity forward in this bird. In all chickens and pigeons, which can have a quite heavy crop, the head-neck-crop weight is less than $20 \%$ of the total body weight, but in parrots and the hoatzin, it is greater than $20 \%$. This disproportion between crop and torso is a second cause of perturbation of the bio-morphological equilibrium, because a large frontal weight diminishes the ability to fly due to unfavorable weight distribution. Observations on living pigeons on one side, and kakapos and hoatzins on the other, show this very clearly (Böker 1929, p. 156).

In hoatzins and kakapos, this perturbation became so strong that it once again, for the second time, triggered deep anatomical reactions: for a stronger lifting capacity the wing expanded, i.e., the remiges grew in length, and the larger frontal weight was attempted to be balanced by a much elongated tail. The hoatzin - basically a long-tailed cuckoo - easily succeeded in this, without a doubt thanks to orthogenetic forces. However, the kakapo - a short-tailed cockatoo, compared to long-tailed parakeets or macaws - did not succeed. Despite these countermeasures, their ability to fly remained impaired. Thus, a complete compensation for the disrupted weight balance seems to be impossible. The skeleton of the arm reflects this in a progressive change of proportions, in which, through "directed variation," the proportions of wings for lift flight are transformed into wings that lack the ability to fly (Böker 1929, p. 159; 1935, p. 121); until now, due to a lack of materials, this can be shown only in the hoatzin, however. A third and once again far-reaching anatomical reaction to the disrupted weight distribution shifted the crop in front of the sternum, i.e., as close as possible to the center of gravity. This very clearly is repeated in the ontogenesis of the hoatzin, which I investigated. ${ }^{13}$

13 To some degree Böker's approach to link developmental with evolutionary studies followed Haeckel's biogenetic law (but see below).
In adults a measure of this is the angle between the spine and upper level of the thorax, since it is $70^{\circ}$ in pigeons, $40^{\circ}$ in Opisthocomus, and $30^{\circ}$ in Stringops. Despite all this, in the hoatzin the frontal weight is still too large, so that the bird at rest cannot keep an upright position. Instead, it lowers itself onto the branch where it sits, which made it develop a callus on the sternum that can already be detected in embryos! In contrast, the kakapo became almost entirely a ground dweller and relinquished the ability to fly.

This phylogenetically acquired migration of the crop, which today must be carried out as early as during embryogenesis, disturbs the embryonic development of chest muscles and the sternum. This is the third cause, to which at this point the organism can react only in very limited ways.

The following numbers show the strong perturbation of the development of flight musculature in the hoatzin and kakapo: crop-less flyers have chest muscles of $9-12 \%$ of their total weight, pigeons with crops $17 \%$, parrots $15-22 \%$, and, by contrast, Opisthocomus exhibits only $12 \%$ and Stringops only $3 \%$ chest muscles. This means: Stringops had to relinquish the ability to fly; the large crop and enormous intestinal tract crush - figuratively speaking - the entire chest muscle inside the highly confined egg. The kakapo can do without flying, because it inhabits mountainous terrain, and it actively reacts to this once more in an entirely new way. It is the first member in a series towards progressive striding on land, a series in which the kiwi and the cassowary represent advanced members. This can be seen in the length of legs: at a torso length of 20 , the total leg length in the tree-dwelling cockatoo is 53; in Stringops, 71. Also, the proportions of the phalanges come closer to those of flightless birds and stand in clear contrast to those of tree-dwelling birds (Böker 1935, p. 136, Fig. 143). The fate of the giant pigeon's genera Pezophaps and Dido [sic], ${ }^{14}$ which are now extinct on the islands, was to become flightless birds in a very similar way. This development shows what lies ahead for the kakapo, if dogs and humans - those two dangerous predators - continue to invade its mountain forests.

Entirely different is the case of the hoatzin. It is a swamp forest dweller and cannot fully give up flight; however, it is the only extant species, genus, and order ${ }^{15}$ i.e., it is extremely vulnerable to environmental conditions. The adult bird has no specific natural enemies, but the poorly balanced nestlings are surprisingly easily mobile at an early developmental stage. They can climb with their feet, hands, and beak, and, if they fall into water, can even escape by diving.

\footnotetext{
${ }_{14}$ Böker means the dodo (Raphus cucullatus).

15 On problems related to the taxonomic position of Opisthocomus
} hoazin, see footnote 10 . 
All of this doubtlessly points towards an active reaction, so it is secondary and does not have anything to do with primitivity, with similarities to Archaeopteryx! $!^{16}$ But one cannot avoid the following impression: one more perturbation of the bio-morphological equilibrium, and Opisthocomus, too, will go extinct, because it seems to me that its ability to react is coming to an end!

In this complicated example we have seen in two very different birds with interesting convergence, how threefold perturbations of the bio-morphological equilibrium, which occur in logical consequence correlatively one after another, again and again are answered by anatomical reactions. Mechanical factors were significant triggers, but the responses to them were anything but mechanistic. It is entirely impossible that the reactions could have been realized through passive random events, through mutation and selection. They were only possible through holistic, i.e., meaningful and forward-looking, active reaction. These reactions were not hereditarily new "characteristics," not new "anatomical features," but complex processes, which always had to be directed towards maintaining the harmony of the whole. Unsuited random mutations, which were deleted through selection so long as a favorable coincidence was lacking, had to be avoided. Instead, internal meaningful structures, i.e., anatomical constructions, had to be maintained holistically functional. No single genes were allowed to change, but complex combinations of genes as a whole had to be maintained in harmony!

From this arises a thought, which, up to this point, undoubtedly has never been fully grasped, and whose clarification will surely contribute to bridging the differences between the exact, experimenting geneticists and the phylogenetically thinking morphologists.

We must differentiate sharply, whether we want to identify perturbations of the bio-morphological equilibrium and the subsequent anatomical reactions in phylogenesis, or whether we want to study how the technics of individual development unfolds during ontogenesis.

As is generally known, ontogenesis can only directly represent ontogenesis, never phylogenesis, as highlighted by Naef (1920). Ontogeny must realize development with its own technics, and this technical process does not have to be identical with the process of phylogenesis (see the phylogenesis and ontogenetic development of the Lig. teres femoralis [sic], ${ }^{17}$ Böker 1934, as well as discussion in Nauck and conclusions). Often so-called "caenogeneses" are brought about

\footnotetext{
${ }^{16}$ Earlier systematic biologists speculated that the hoatzin was descended from Archaeopteryx. In line with current taxonomic views, Böker rejected this theory.

17 Böker means "Lig. teres femoris," i.e., the ligament of the head of the femur.
}

by the technics of ontogenesis, which can only be transferred to "palingeneses" through special research methods (Böker 1935, p. 16).

The experimental account of inheritance is the technics of inheritance, a mechanics of inheritance. The process of active reaction happens during phylogeny. But the way in which this process is transferred to the germ plasm, so that the phylogenetic process occurs in ontogeny as a hereditarily fixed process, is a technical problem.

The question "How can a genetic change occur as a consequence of a vital change of behavior in an animal?" is a quite different one than "How is an anatomical construction reconstructed, if the vital expressions of an animal had to change?" The second question is a phylogenetic one, the first is a technical, hereditary-technical question. The problem of parallel induction, the transfer from soma to germ cells is, therefore, a physiological, technical question that does not concern the problem of phylogenetic reaction. The process of inheritance is a mechanism, which occurs purely passively, and which remains passive and constant until it is once again replaced by active reaction.

Like the constant process of inheritance, the general processes of ontogenetic development are a fixed mechanism, as they are, tellingly, investigated by the "developmental mechanist." All processes examined by the physiologist are also technical processes that can be explained by the laws of chemistry and physics. But it must be clear that the investigation of technics should not be the aim of our efforts in biology; it can only be a subarea of our research. We have to recognize that, behind the fixed mechanisms that can dominate the picture of life processes entirely, there are active, animated living occurrences ${ }^{18}$ in the background, ready to come to the forefront at any time. Without the lawful regularity of chemical and physical processes in organisms, there is no physiological-anatomical equilibrium, but only sickness! Without the lawful regularity of inheritance processes there is no ethological-anatomical equilibrium, but only aimless and unrestrained variation! But without activity there is no renewal of bio-morphological equilibrium, no reconstruction of perturbed anatomical constructions, no adaptation, but only subservience to chance, chaos, destruction!

Activity expresses itself in memory, in the ability to select stimuli, in self-control and self-correction, i.e., in anatomical reaction. As long as external influences do not entail a perturbation of the biological-morphological equilibrium of the organism, the organism does not feel compelled to change its anatomical constructions in any way. But as soon as not only single individuals but the species as such, i.e., at least all individuals that live in the same geographical area, are perturbed in their ecological-ethological equilibrium,

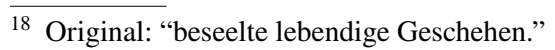


an anatomical reaction in the form of a reconstruction will follow. Here, it is irrelevant whether the perturbation originates in the environment or if it consists of a change in manifestations of life, ${ }^{19}$ and it is irrelevant whether these changes are enforced or voluntary. An active reaction can also affect external traits, but it primarily concerns anatomical constructions. While passive mutations are coincidental, and neither do they relate to the future nor carry a purpose, active reactions always are creating [functionally] meaningful structures.

Active reaction has two requirements: the presence of a physiological ability to react and the readiness to react.

Both requirements do not always need to be fulfilled in the same way. If the shaping stimulus, which was induced by a perturbation of the bio-morphological equilibrium, is strong enough, it can force a reaction even given missing readiness to react, just as conversely, a deficient ability to react can be improved by an urgent shaping stimulus, even though this is significantly harder. Very often a weak stimulus is sufficient to influence the form. Then, the systematic biologist does not always feel compelled to speak of separate species. An example: "large-headed" and "pointnosed" eels, which both have to be counted in the species Anguilla vulgaris. ${ }^{20}$ Sometimes, a change in environmental conditions and manifestations of life does not lead to an anatomical reconstruction, because the change did not become a perturbation of the bio-morphological equilibrium. Examples: the trout still has a set of teeth typical for predator fishes, despite having become a non-predatory fish; prehistoric forms like the lancelet, Branchiostoma, and the lungfish, Dipnoi, have remained unchanged since prehistoric times (e.g., Ceratodus certainly since the Triassic), while other animal groups underwent incredible transformations in the same time span. The explanation for this may be as such: The ability to react in Dipnoi was very low; because of this they are almost entirely extinct today and only exist in a few retreats. That these remnants still exist, however, is based on the likelihood of them having not experienced any profound perturbations of their biomorphological equilibrium, apart from the complication of breathing under water.

But it is well known that sometimes environmental influences can lead very easily to alterations of the anatomical structure of animals. These then are modifications that do not influence the process of inheritance. Goldschmidt (1928) says:

\footnotetext{
19 Original: "Lebensäusserungen."

20 Anguilla vulgaris is today known under the species name Anguilla anguilla.
}

Whatever may be the origin of the (species) transformation, it has nothing to do with the modification of the body through influences of the external world. The effect of external influences is therefore eliminated as a constructive force from the problem of evolution, it only comes into consideration as an eradicating force for non-viable variations (mutations).

A beautiful example of this are the experiments by Woltereck on Daphnia (cited in Plate 1933, p. 1131): the height of its helmet-like structure was reduced in adverse conditions. ${ }^{21}$ But even after 80 generations, hereditary fixation could not be achieved, because this is merely a physiological-anatomical reaction, a modification, but not an active reaction to the perturbation of the bio-morphological equilibrium. The environmental influences remained as operating stimuli and did not become structuring stimuli. Because of this, Kühn (1935)'s sentence is, of course, correct: “The hereditary dispositions, which make up the hereditary material, determine the extent and the kind of interaction between lifeform and environment." But when he writes: "the hereditary dispositions can only have an effect as far as the environment allows it, the environment can only have an influence as far as the disposition accommodates it," then this is only correct as long as the operating stimuli do not become structuring stimuli, i.e., only until a perturbation of the bio-morphological equilibrium occurs. Once the latter happens, the passive modification becomes an anatomical reconstruction through active reaction. For as long as the reaction lasts over the course of generations, and thus the reconstruction could not yet reestablish the bio-morphological equilibrium, so long the ontogeneses show that there is no complete heritability. ${ }^{22}$ An example: crossbills, Loxia, in which the last development of the crossed beak is achieved only through the species-appropriate use of it, which was shown experimentally and through comparison (Huber 1933, p. 584). Once the reconstruction is completed, the heritability is also usually established.

Once we know in detail when an environmental influence takes the form of a perturbation of the bio-morphological equilibrium, i.e., when a modification turns into an anatomical reconstruction, then we can reveal the time needed to hereditarily fix such a transformation of species. We will then likely see that long geological timespans are not always necessary, but instead often just decades are necessary to reveal clear changes in constructions. One example of this

\footnotetext{
${ }^{21}$ Some species of Daphnia can develop protective helmet-like structures on the head when they detect invertebrate predators (i.e., elongated helmets can be induced with predator kairomones). Thus, in contrast to Böker's description, helmet-like structures are elongated (not shortened) in adverse conditions.

22 Original: "Erbfestigkeit."
} 
might become rufous hornero, Furnarius, of which I became aware in Brazil (Böker 1932, p. 82).

It depends on the intensity and speed of perturbating influences, and on the degree of the organisms' ability and readiness to react. Every single time, a transformation of species through reconstruction is an active, a holistic event, never a passive mechanistic one.

A. Meyer (1934) describes this idea as follows: "Organisms are never only passive adaptations to the organic environment." This means that conditions of milieus can never be the final cause for the actual transformation of organisms. Environments, as such, can at best have a stimulating and triggering role. The actual reorganization of organisms is always an active act of creation of the organisms themselves that matches their inner world. ${ }^{23}$ Both Darwinism and Lamarckism have ultimately failed because of their conflation of active adaptive insertion ${ }^{24}$ with passive adaptation. Both are theories of milieus that attribute to the environment active, creative forces in the process of species transformation. Suchlike will never exist. However, I do not doubt that one day the inheritance of actively created constructions, which are desired by the organism, can be secured (whereby this desire has nothing to do with consciousness), but never will there be an inheritance of such traits that are only caused passively by the conditions of the environment.

Thus, the theory of active reaction is not identical with the present theory of the "inheritance of acquired characteristics," so-called Lamarckism, because reconstructions concern much more than just changes of single traits or any characteristics - a term that should be avoided in anatomy altogether.

But active reaction is not the only manner of species transformation, because it cannot be denied that the following three options also may change species under certain circumstances, namely direct influence, orthogenesis, and mutation.

If all individuals of a species are exposed to the same environmental conditions, then all individuals will change in

\footnotetext{
23 Böker draws here on Jakob von Uexüll's distinction of inner world ("Innenwelt") and outer word ("Außenwelt"). It states that the environment is constructed through the inner sensual perception of the organism. At the same time, the outer world is affected by the acting organism and reciprocally affects the perceiving organism (see Uexküll J.v. (1909) Umwelt und Innnenwelt der Tiere. Springer, Berlin).

24 Original: "Einpassung." Coined by Jakob von Uexküll, this term describes the close and reciprocal integration of organism and environment. For Uexküll this integration does not come in degrees. Instead, it is understood teleologically. This means that "Einpassung" is established by the organism's building-plan and a pre-established environment. In contrast, for Böker active "adaptive insertion" through reconstructions can come in degrees (e.g., it can increase over generations) and can be more or less successful.
}

very similar ways, and directly influenced anatomical traits occur so regularly and generally that the systematic biologist has to consider them as species' characteristics.

Often, it is not yet decided at all, if and to what extent these species' traits are heritable, so whether they should be considered as modifications or reconstructions. As an example of this, the facts of Gloger's rule, Allen's rule, and Bergmann's rule can be mentioned.

Gloger's rule tells us that the melanin pigmentation of warm-blooded creatures depends on climatic factors, so that the polar white, desert yellow, savanna red, and jungle brown are caused by it; Allen's rule concerns the relative length of protruding body parts: long ears in the desert, short ears in the arctic; finally, Bergmann's rule determines that body size and weight depend on temperature: small species live in warm climates, large in cold ones (Rensch 1929, 1933).

Orthogenesis describes a development that depends on inner factors, which forcibly continues in the same direction and that can even lead to very peculiar, extreme forms. Examples of this are the increasing growth of all species of a certain genus, for example, in elephants, and the formation of excessive degrees of certain beak shapes, antlers, decorative plumes, and so on. As part of orthogenesis, one needs to count a certain bias in the ability to react, which becomes apparent, for example, in the fact that a large group of parrots was able to develop a long tail, while another group remained distinctly short tailed, which biologically disrupted their ability to fly (Böker 1932, p. 156). Orthogenesis is a principle of species change that always has something pathological about it, and which therefore cannot be of crucial importance.

Compared to the above, of even less significance for meaningful species transformation is passive mutation. Mutation only leads to species transformation if it changes indifferent features, which must not cause a perturbation of the biology and morphology of the animal, otherwise either selection would intervene through eradication or an active reaction would have to save what can be saved.

By far the most important role in the phylogenetic processes of species transformation and species formation lies in the ability of active reaction, which, furthermore, dominates all biological occurrences in nature, so that the theory of active reaction to perturbation of bio-morphological equilibrium must be the most important foundation of biological thinking. Besides this, there remains, of course, the theory of the laws of inheritance, which, however, neither is nor can be the sole important foundation, so that E. Lehmann (1934) is in the wrong when he writes: "Starting- and center-point of all biological thinking should, therefore, be genetics." Genetics, as far as it is based on the theory of mutation, necessarily and consequentially leads to mechanism! But this we must try to overcome, if we want to reach true biological thinking. 
Phylogeny is the history of organisms, anatomically speaking, the history of changes in form, and it is therefore, biologically speaking, the history of living conditions under which organisms survived, and under which changes in form occurred. But historical science does not only have to register, it also has to try interpreting meaning and to trace causative factors (Meyer 1926). Phylogeny is significantly more than phylogenetic systematics, more than genealogy.

If the change of form is caused only by mutation, thus by random variables, then phylogeny is nothing but a registration of consecutive mutations. But if change of form is a reaction to perturbations of the bio-morphological equilibrium, following changes in environmental conditions and manifestations of life manifestations, then phylogeny is truly a historical science, the history of reconstructions and their causative conditions.

Just as in biology as a whole the opposition of mechanistic thinking of the past and biological thinking of the future calls for a resolution, so too must the opposition and the scope of these two schools of thought be sharply recognized in genetics and the theory of descent. I want to outline this contrast as follows: The theory of mutation rests on static, mechanistic thinking, it thinks in terms of states, it deals with technics of inheritance, it is inheritance mechanics; mutations are hereditable random variations, they change anatomical features, they are subject to Mendel's laws.

The theory of active reaction, which is much more than what is understood by the two terms Lamarckism and inheritance of acquired characteristics, is based on dynamic and biological thinking; it thinks in terms of processes, processes of phylogeny and function; it is based on geneticconstructive thinking. Reactions change anatomical constructions, these reconstructions gradually become fixed in the hereditary material, and, once they regain as a whole their bio-morphological equilibrium, remain constant until they are forced again to react to new perturbations of the bio-morphological equilibrium.

Knowing these theoretical foundations of our thinking is of great importance for biology as a whole, because the ability to explain and to understand the appearances of life depends on it. The decision on the value of these theoretical problems ultimately depends on their practical relevance. And this again lies in medicine. Healing does not merely mean influencing passive processes - that would be a mechanistically understood medicine - instead, healing means influencing active occurrences in the living organism in a way that also affects passive processes. If both are united as a whole, then we deal with biologically understood medicine.

In general, the physician does not deal with phylogenetic reactions, but instead with individual physiological reactions. But if we would not recognize the first, then we would also have to understand the latter as coincidental, unavoidable occurrences based on developmental mechanisms, inheritance mechanisms, the chemical and physical mechanisms. But the physician always comes across the active occurrence, the living, the animated, that often thoroughly defies mechanics, and always the physician must consider where phylogenetical processes, in the form of progressive or regressive reconstructions, are still in progress!

If we are to overcome thinking only in terms of chemical and physical processes, if we are to overcome the passive mechanism in biology and therefore in medicine as well, then we have to free ourselves from thinking of passive mutations as the exclusive causes of species transformation. Like the general chemico-physical processes, so too are processes linked to inheritance factors of extraordinary importance for maintaining a certain direction in development. Figuratively speaking, we can compare the passive with the reins and blinders that one would put on a nervous horse to prevent aimless spooking and bolting. Had organisms not their reins through passive factors, they would run the risk of varying aimlessly and unrestrainedly as a reaction to all kinds of external stimuli. If there was, beyond the passive occurrences, not the active that is capable of overcoming the passive, then there would be, phylogenetically speaking, no species transformation, which could mean adaptation or improvement, and there would be no healing for sick individuals, no meaningful reaction to perturbations of the physiological-anatomical equilibrium. The sum of passive factors is, to use another metaphor, comparable to an automobile that one puts into motion on a country road with locked steering. Without the active, without the animated human behind the wheel, it will end up in a ditch shortly thereafter. In the transformation of species active reaction precedes passive mutation, and it gives mutations a meaning and aim. If an individual's passive, chemico-physical factors are impaired due to sickness, then the readiness to active reaction must return these factors to equilibrium. Thus, the physician must not forget the active, the animated over the passive occurrences!

The foundations for this are created not by medicine alone, but by the entire natural history of humans, which rests on a natural science that consists not only of mathematical sciences, chemistry and physics, physiology and genetics, but that is also rooted in the biological sciences, zoology, psychology, and so on. Therefore, anatomy as a grounding ${ }^{25}$ of medicine cannot merely be descriptive and topographical anatomy, but, by understanding phylogenesis and function, it must become comparative biological anatomy.

$\overline{25}$ Original: "Vorschule." 
Funding Open Access funding enabled and organized by Projekt DEAL.

Open Access This article is licensed under a Creative Commons Attribution 4.0 International License, which permits use, sharing, adaptation, distribution and reproduction in any medium or format, as long as you give appropriate credit to the original author(s) and the source, provide a link to the Creative Commons licence, and indicate if changes were made. The images or other third party material in this article are included in the article's Creative Commons licence, unless indicated otherwise in a credit line to the material. If material is not included in the article's Creative Commons licence and your intended use is not permitted by statutory regulation or exceeds the permitted use, you will need to obtain permission directly from the copyright holder. To view a copy of this licence, visit http://creativecommons.org/licenses/by/4.0/.

\section{References $^{26}$}

Bertalanffy Lv (1932) Theoretische Biologie. Bd. I. Berlin.

Böker H (1929) Flugvermögen und Kropf bei Opistocomus cristatus und Stringops habroptilus. Morph. Jahrb., 63.

Böker H (1932) Tiere in Brasilien. Stuttgart.

Böker H (1934) Die Bedeutung des Lig. teres femoris. Verh. anat. Ges. Böker H (1935) Einführung i. d. vergl. biol. Anatomie der Wirbeltiere. I. Bd., Jena.

Goldschmidt R (1928) Einführung in die Vererbungswissenschaft. 5. Aufl., Berlin.
Hartert E, Stresemann E (1927) Grenzfälle des Artbegriffes. J. f. Ornith., 75.

Huber W (1933) Untersuchungen über die Genese der Asymmetrie am Kopf von Loxia curvirostra. Morphol. Jahrb., 71.

Kühn A, Saemmler W, Burgdörfer Fr. (1935) Erbkunde, Rassenpflege, Bevölkerungspolitik. Woltereck H (ed). Leipzig.

Kyle HM (1926) The biology of fishes. London.

Lehmann E (1934) Biologischer Wille. München.

Meyer A (1926) Logik der Morphologie. Berlin.

Meyer A (1934) Ideen und Ideale der biologischen Erkenntnis. Bios, Abhandl. z. theoret. Biologie.

Naef A (1920) Ueber das sogen. biogenetische Grundgesetz. Festschr. f. Zschokke, Basel.

Naegeli O (1934) Allgem. Konstitutionslehre. 2. Aufl., Berlin.

Plate L (1932) Genetik und Abstammungslehre. Z. f. indukt. Abstammungs- u. Vererbungslehre, Bd. 62.

Plate L (1933) Vererbungslehre. 2. Aufl., Bd. 2, Jena.

Rensch B (1929) Das Prinzip geograph. Rassenkreise und das Problem der Artbildung, Berlin.

Rensch B (1933) Zoolog. Systematik und Artbildungsproblem. Verh. d. zool. Ges.

Stresemann E (1926) Uebersicht über die "Mutationsstudien" I-XXIV und ihre wichtigsten Ergebnisse. J. f. Ornith., 74.

Publisher's Note Springer Nature remains neutral with regard to jurisdictional claims in published maps and institutional affiliations.

${ }^{26}$ Reference list adopted from original. 